\title{
Cannabidiol metabolism revisited: tentative identification of novel decarbonylated metabolites of cannabidiol formed by human liver microsomes and recombinant cytochrome P450 3A4
}

\author{
Kazuhito Watanabe ${ }^{1}$ - Noriyuki Usami ${ }^{2}$. Shigehiro Osada ${ }^{1}$. Shizuo Narimatsu ${ }^{3}$. Ikuo Yamamoto ${ }^{2}$. \\ Hidetoshi Yoshimura ${ }^{4}$
}

Received: 4 February 2019 / Accepted: 13 February 2019 / Published online: 1 March 2019

(c) The Author(s) 2019

\begin{abstract}
Purpose The purpose of the present study was to identify the structures of cannabidiol (CBD) metabolites during CO formation by human liver microsomes and human recombinant cytochrome P450 (CYP) enzymes.

Methods CBD was NADPH-dependently metabolized by human liver microsomes and human recombinant CYP enzymes. Less-polar metabolites were analyzed by gas chromatography-mass spectrometry monitoring, and their estimated molecular ions were $\mathrm{m} / \mathrm{z} 286,358$ and 481 after non-derivatization, trimethylsilylation and pentafluorobenzyl oxime formation, respectively.

Results We tentatively identified novel decarbonylated metabolites of CBD as keto-enol tautomers. Among eight major recombinant human CYP enzymes, only CYP3A4 catalyzed the formation of decarbonylated metabolites.

Conclusions CBD was biotransformed to two decarbonylated metabolites, an enol-form (cyclopentadienol structure), and a keto-form (cyclopentenone structure) by human liver microsomes and CYP3A4.
\end{abstract}

Keywords Cannabidiol $\cdot$ Decarbonylation $\cdot$ Metabolism $\cdot$ Human liver microsomes $\cdot$ CYP3A4 $\cdot$ Cyclopentadienol

\section{Introduction}

Cannabidiol (CBD), one of the major phytocannabinoids in cannabis, has a variety of pharmacological effects, such as anticonvulsant, antiemetic, antioxidant, and anxiolytic effects, as well as barbiturate-induced sleep prolongation

Shizuo Narimatsu: Deceased on 6 November 2017.

Hidetoshi Yoshimura: Deceased on 11 July 2018.

Kazuhito Watanabe

k-watanabe@daiichi-cps.ac.jp

1 Daiichi University of Pharmacy, 22-1 Tamagawa-cho, Minami-ku, Fukuoka 815-8511, Japan

2 Faculty of Pharmaceutical Sciences, Hokuriku University, Ho-3 Kanagawa-machi, Kanazawa 920-1181, Japan

3 Faculty of Health and Nutrition, Minami Kyushu University, 5-1-2 Kirishima, Miyazaki 880-0032, Japan

4 Graduate School of Pharmaceutical Sciences, Kyushu University, 3-1-1 Maidashi, Higashi-ku, Fukuoka 812-8582, Japan
[1-3], although this phytocannabinoid lacks psychoactivity, which is associated with its lower affinity for the $\mathrm{CB}_{1}$ cannabinoid receptor [4]. For medical purposes, Sativex, a 1:1 mixture of $\Delta^{9}$-tetrahydrocannabinol and CBD as active ingredients, has been clinically used for the treatment of neuropathic pain and spasticity [5-7]. In addition, several studies have suggested that CBD has various medical benefits against a range of diseases, in particular cancer $[8,9]$ and drug-resistant epilepsy in children [10, 11].

CBD is metabolized in experimental animals and humans in vitro, as well as in vivo [12-15]. The primary metabolic reactions of CBD are allylic hydroxylations at the 6- and 7-positions that are catalyzed by cytochrome P450 (CYP) enzymes mainly expressed in the liver. Our previous study showed that CYP3A4 and CYP2C19 have major roles in the metabolism of CBD in human liver microsomes [16]. In earlier studies, we demonstrated that CBD generated CO during mouse liver microsomal metabolism [17, 18]. It was speculated that $\mathrm{CO}$ could be formed from CBD by CYP enzymes, in which the phenolic hydroxyl groups of $\mathrm{CBD}$ are a possible source for the $\mathrm{CO}$ formation, although a counterpart metabolite of $\mathrm{CBD}$ after $\mathrm{CO}$ formation had not 
been detected. In the field of forensic science, it is important to clarify the overall metabolism of CBD. The purpose of the present study was to tentatively identify the structures of CBD metabolites during $\mathrm{CO}$ generation by human liver microsomes and human recombinant CYP enzymes.

\section{Materials and methods}

\section{Chemicals}

CBD was isolated and purified from cannabis leaves by the method of Aramaki et al. [19]. The purity of CBD was confirmed to be more than $98 \%$ by gas chromatography (GC). NADP, NADPH, glucose 6-phosphate and glucose6-phosphate dehydrogenase were purchased from Oriental Yeast Co. (Tokyo, Japan); N,O-bis-(trimethylsilyl)trifluoroacetamide with $1 \%$ trimethylchlorosilane and pentafluorobenzylhydroxylamine (PFBHA) hydrochloride were from Wako Pure Chem. Co. (Osaka, Japan). Other chemicals and solvents used were of the highest quality commercially available.

\section{Enzyme sources}

Pooled human liver microsomes (HLMs) and microsomes from baculovirus-infected insect cells expressing human CYP enzymes (CYP1A2, CYP2A6, CYP2B6, CYP2C9, CYP2C19, CYP2D6, CYP2E1, and CYP3A4 with cytochrome b5) were purchased from BD Gentest (Woburn, MA, USA).

\section{CBD metabolism}

HLMs (20 $\mu \mathrm{g}$ protein) or human recombinant CYP enzymes $(10 \mathrm{pmol})$ were used as enzyme sources. The incubation mixture consisted of $32 \mu \mathrm{M} \mathrm{CBD}$, an enzyme source, an NADPH-generating system (0.5 mM NADP, $10 \mathrm{mM}$ glucose 6-phosphate, $10 \mathrm{mM}$ magnesium chloride, and 1 unit of glucose-6-phosphate dehydrogenase) or $2 \mathrm{mM}$ NADPH, and $100 \mathrm{mM}$ potassium phosphate buffer ( $\mathrm{pH}$ 7.4) to make a final volume of $0.5 \mathrm{~mL}$. The mixture was incubated at $37{ }^{\circ} \mathrm{C}$ for $30 \mathrm{~min}$ (or $60 \mathrm{~min}$ for recombinant CYP enzymes) and then extracted with $4 \mathrm{~mL}$ of $n$-hexane after addition of $0.5 \mathrm{~mL}$ $1 \mathrm{M}$ monopotassium phosphate. Two additional incubations without enzyme sources or the NADPH-generating system were processed in the same way. A portion of the $n$-hexane extract was evaporated to dryness, and dissolved in $50 \mu \mathrm{L}$ dry acetonitrile for direct gas chromatography-mass spectrometry (GC-MS) analysis. The remaining $n$-hexane extract was derivatized by trimethylsilylation as described previously $[16,20]$ or by pentafluorobenzyl oxime formation using the method of Kobayashi et al. [21].

\section{Gas chromatography-mass spectrometry}

GC-MS was conducted on a 7890B GC system (Agilent Technologies, Santa Clara, CA, USA), equipped with a DB5MS capillary column $(30 \mathrm{~m} \times 0.25 \mathrm{~mm}$ i.d., film thickness $0.25 \mu \mathrm{m}$; Agilent Technologies) and a JEOL JMSQ1500 mass spectrometer (JEOL Ltd., Akishima, Japan). The GC-MS conditions were as follows: injection mode $1-\mu \mathrm{L}$ sample injection and splitless; injection port temperature $250{ }^{\circ} \mathrm{C}$; carrier gas $\mathrm{He}$; flow rate $1 \mathrm{~mL} / \mathrm{min}$; column temperature $50{ }^{\circ} \mathrm{C}$ (1-min hold $), 25{ }^{\circ} \mathrm{C} / \mathrm{min}(5 \mathrm{~min}), 10$ ${ }^{\circ} \mathrm{C} / \mathrm{min}$ and $300{ }^{\circ} \mathrm{C}$ (8-min hold); ion source temperature $180{ }^{\circ} \mathrm{C}$; interface temperature $240{ }^{\circ} \mathrm{C}$; ionization conditions $70 \mathrm{eV}$ in full scan mode (50-650 amu); emission current $100 \mu \mathrm{A}$. Estimated molecular ions of CBD metabolites were monitored at $m / z, 286$ for non-derivatization, at $\mathrm{m} / \mathrm{z} 358$ for trimethylsilylation and at $\mathrm{m} / \mathrm{z} 481$ for PFBHA derivatization. Under these conditions, the retention times of the underivatized CBD and the trimethylsilyl (TMS) derivative of CBD were 13.33 and $11.44 \mathrm{~min}$, respectively.

\section{Results and discussion}

The proposed metabolites of CBD could be tentatively identified as molecular ions of CBD decarbonylated metabolites. As shown in Fig. 1a, two peaks with retention times at $10.90 \mathrm{~min}(\mathrm{M}-1)$ and $11.00 \mathrm{~min}(\mathrm{M}-2)$ appeared in the extracted ion chromatogram (XIC) recorded by extracted ion monitoring of an estimated molecular ion at $m / z 286$. The retention times of M-1 and M-2 were earlier than that of the parent compound, CBD (13.33 min). M-1 (Fig. 1b) and M-2 (Fig. 1c) showed similar mass spectra, with a molecular ion at $\mathrm{m} / \mathrm{z} 286$ and typical fragment ions at $m / z 203$ and 134. The fragment ion at $m / z 203\left(\mathbf{M}^{+}-83\right)$ is based on a similar fragmentation to that of CBD [22, 23], which is produced by retro Diels-Alder cleavage of the terpene ring and a methyl radical [23]. The base peak at $m / z 134$ is produced by the release of a CBD limonene moiety. These results probably indicate that CBD decarbonylation occurred in its olivetol moiety, as postulated by our earlier studies [17, 18], and that M-1 and M-2 seem to have similar structures, suggesting they are isomers of each other. When HLMs or the NADPH-generating system was omitted from the incubation mixture and processed in the same way, M-1 and M-2 were not observed on the XIC (data not shown).

Mass shifts and fragmentations by chemical derivatization can provide extremely useful information for the identification of unknown metabolites. After trimethylsilylation of the CBD reaction products, the peak at $10.90 \mathrm{~min}$ 

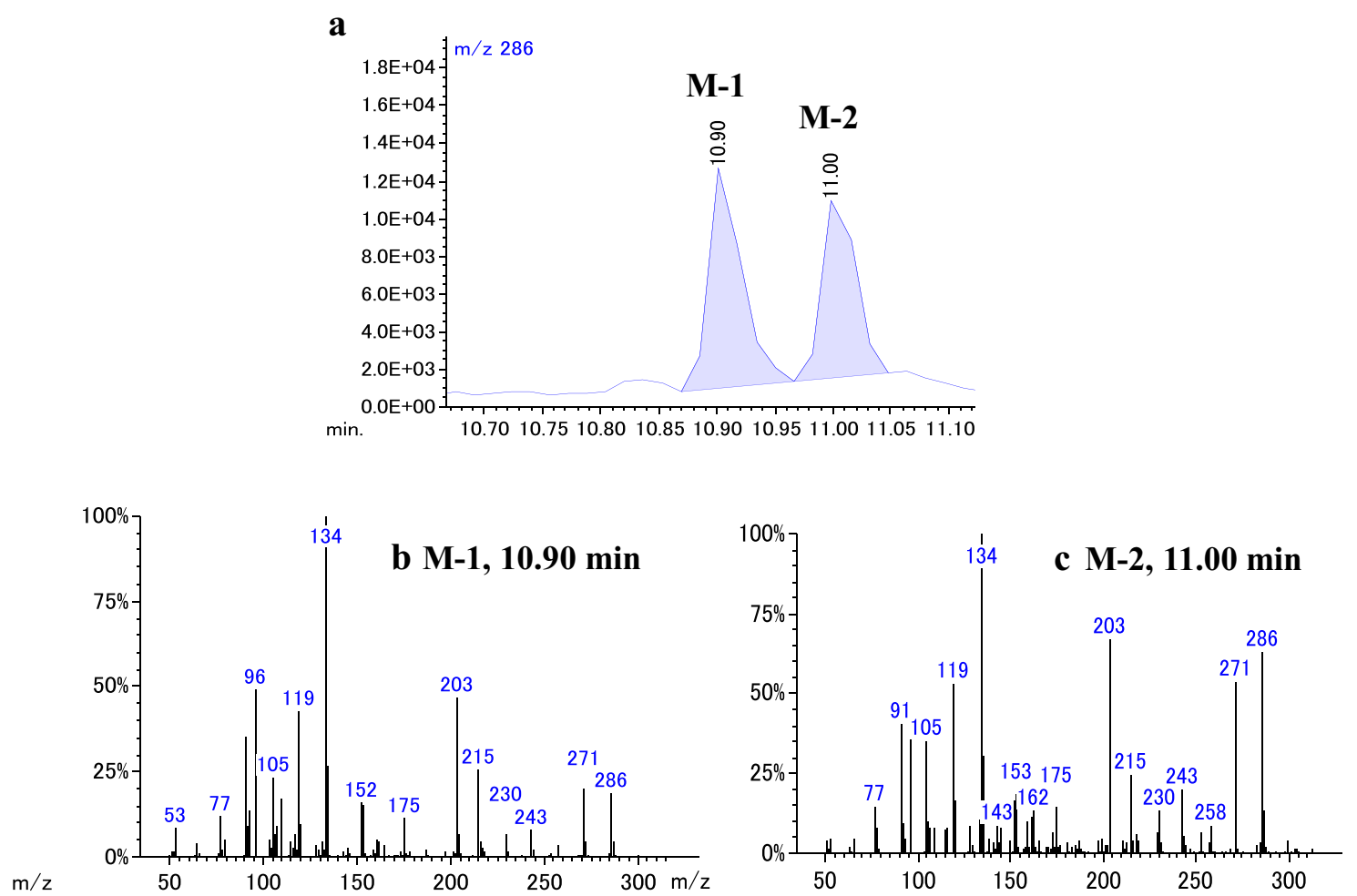

Fig. 1 Extracted ion chromatogram (XIC) and mass spectra of decarbonylated metabolites of cannabidiol (CBD) formed by human liver microsomes (HLMs) in the underivatized forms. a XIC at $\mathrm{m} / \mathrm{z}, 286$

disappeared (Fig. 2a), and then a new peak at a retention time of 10.16 min appeared on the XIC recorded by extracted ion monitoring of an estimated molecular ion of a TMS derivative at $\mathrm{m} / \mathrm{z} 358$ (Fig. 2b). The mass spectrum of the peak showed a molecular ion at $m / z, 358$ and a base peak at $\mathrm{m} / z 290$ (Fig. 2c), which was a similar fragmentation pattern to TMS derivatives of CBD and their monohydroxy metabolites reported previously [13, 23]. In contrast, M-2 was not derivatized by trimethylsilylation, and was present at the same retention time (Fig. 2a). These results indicate that the structure of M-1 has one hydroxyl group, and M-2 has no hydroxyl group, although both metabolites have the same molecular weight.

In the pyrrolysis of phenol and dihydroxy benzene derivatives, $\mathrm{CO}$ is known to be a major final product, and cyclopentadiene, cyclopentadienol, and cyclopentenone were formed as intermediate products through fulvenone radical species [24, 25]. Considering these chemical findings and the data in Figs. 1 and 2, the possible structures of M-1 and M-2 are proposed to include keto-enol isoforms of cyclopentadienol and cyclopentenone-type structures. This possibility was further supported by an additional derivatization with PFBHA to form an oxime. PFBHA reacts with carbonyl functional groups, but not hydroxyl groups, to produce the corresponding oximes, which have been analyzed by showing M-1 and M-2 peaks, b, $\mathbf{c}$ mass spectra for M-1 and M-2 peaks, respectively

GC-MS [21, 26]. CBD metabolites formed by HLMs were processed with PFBHA, and analyzed by GC-MS using extracted ion monitoring of its estimated molecular ion of the M-2 oxime derivative at $m / z$ 481. As shown in Fig. 3a, two main peaks appeared on the chromatogram at 14.23 and $14.87 \mathrm{~min}$, both of which had a molecular ion at $\mathrm{m} / \mathrm{z} 481$ and a base peak at $\mathrm{m} / \mathrm{z} 347$, and a loss of the limonene moiety $\left(\mathrm{M}^{+}-134\right)$ (Fig. 3b, c). In PFBHA derivatization, it is well known that two $E / Z$ oxime isomers are produced from a carbonyl compound, and are observed as double chromatographic peaks with the second peak generally much more prominent than the first peak [26].

In earlier studies, we suggested the possible role of CYP enzymes in CO formation during CBD metabolism by mouse liver microsomes $[17,18]$. The $\mathrm{CO}$ formation was significantly inhibited by the addition of typical CYP inhibitors including SKF 525-A [17]. Among eight major recombinant human CYP enzymes (CYP1A2, CYP2A6, CYP2B6, CYP2C9, CYP2C19, CYP2D6, CYP2E1, and CYP3A4) examined in the present study, only CYP3A4 exhibited catalytic activity for the formation of decarbonylated metabolites of CBD. None of microsomes expressing other seven CYP enzymes and control baculosomes showed substantial formation of the decarbonylated metabolites. In GC-MS analysis of reaction products by CYP3A4, a similar 

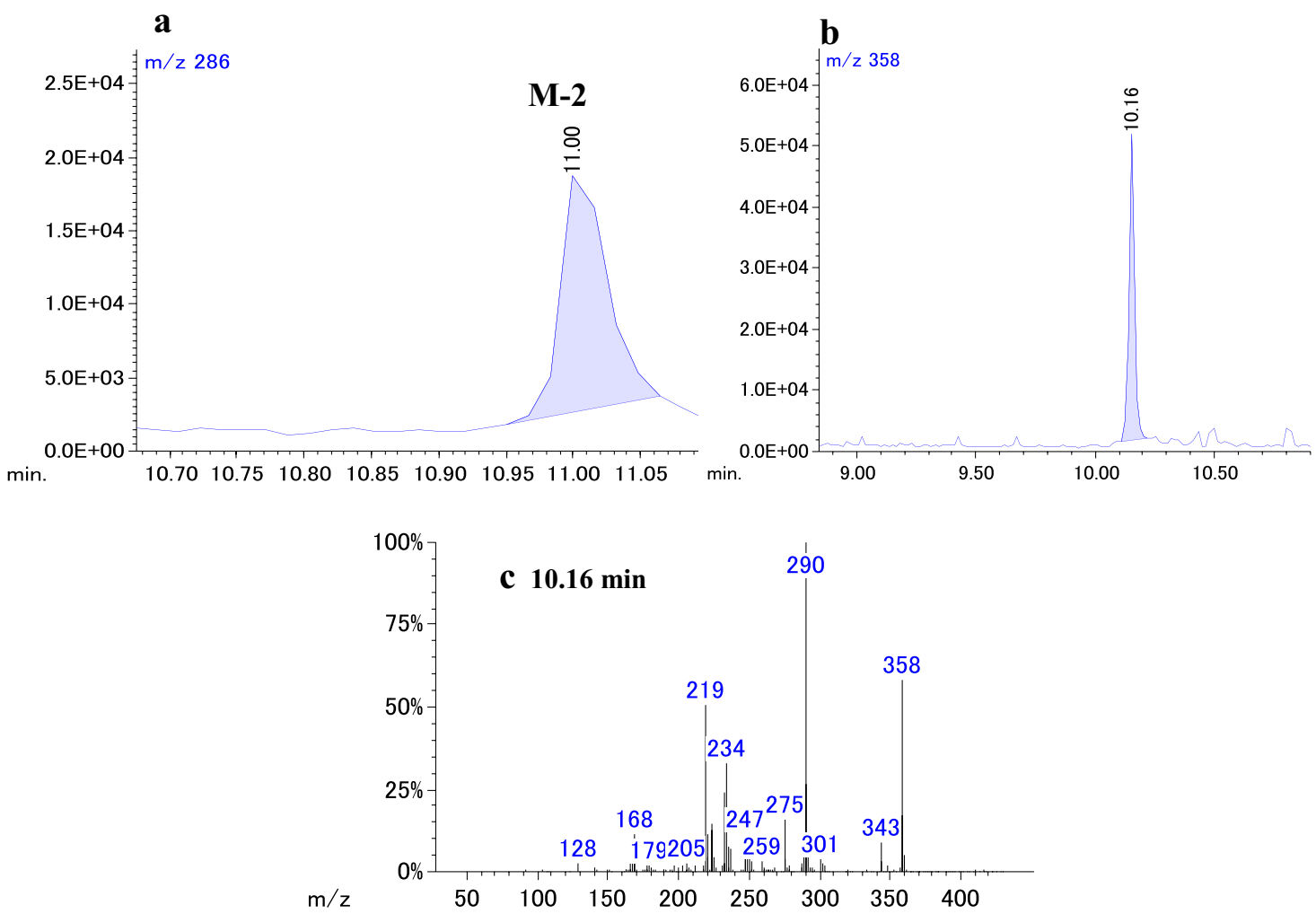

Fig. 2 XICs and the mass spectrum of the CBD metabolites after trimethylsilylation. a XIC without derivatization at $m / z$ 286, b XIC after trimethylsilylation at $m / z, 358$, c mass spectrum of the CBD metabolite after trimethylsilylation

mass chromatogram and mass spectra to those of M-1 and M-2 in Fig. 1 were observed as shown in Fig. 4. By trimethylsilylation and PFBHA oxime derivatization, the same mass shifts and fragmentations as those in Figs. 2 and 3 were also observed for two decarbonylated metabolites formed by human recombinant CYP3A4 (data not shown). These results strongly suggest that CYP3A4 is the main enzyme for the decarbonylation of CBD by HLMs.

\section{Conclusions}

In this study, we tentatively identified two less-polar metabolites of CBD formed with human liver microsomes and CYP3A4 as shown in Fig. 5. Both metabolites are formed from CBD by decarbonylation, and are present in keto-enol tautomers. Two metabolites, an enol-form and a keto-form, could be analyzed by GC-MS as a TMS derivative and PFBHA oximes, respectively (Fig. 5). This is the first report 


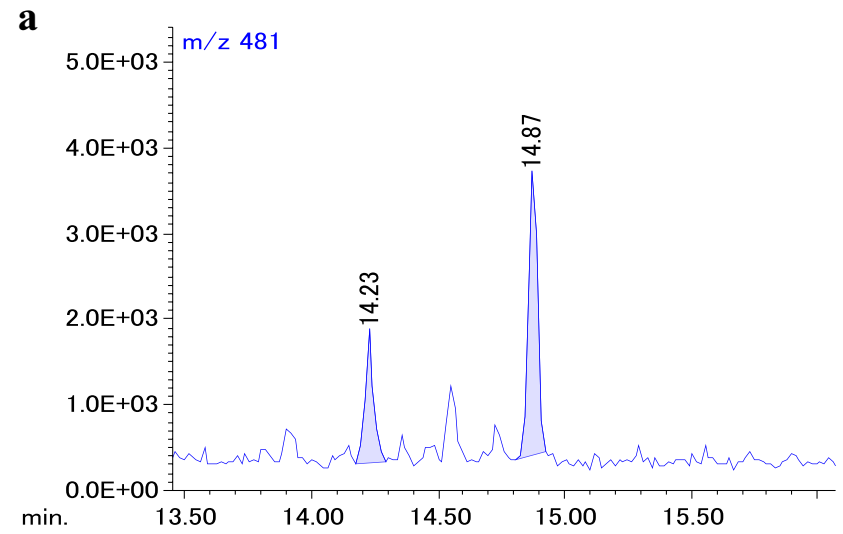

b $14.23 \mathrm{~min}$

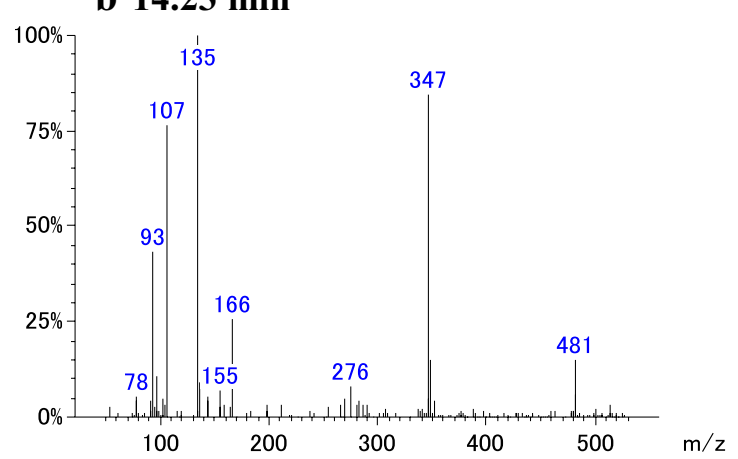

c $14.87 \mathrm{~min}$

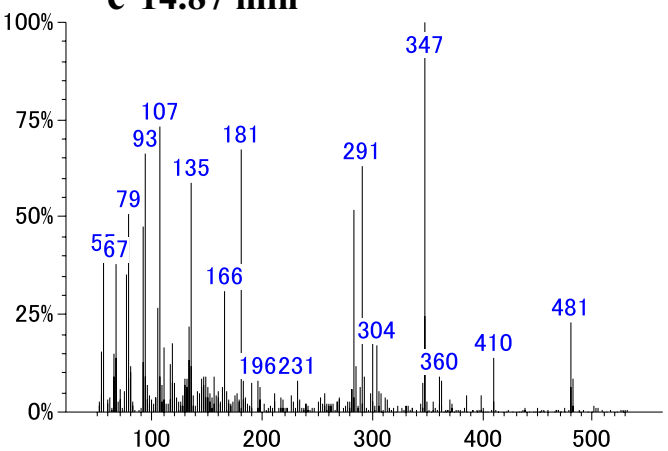

Fig. 3 XIC and the mass spectra of pentafluorobenzylhydroxylamine (PFBHA) derivatives of CBD metabolites formed by HLMs

$\mathbf{a}$
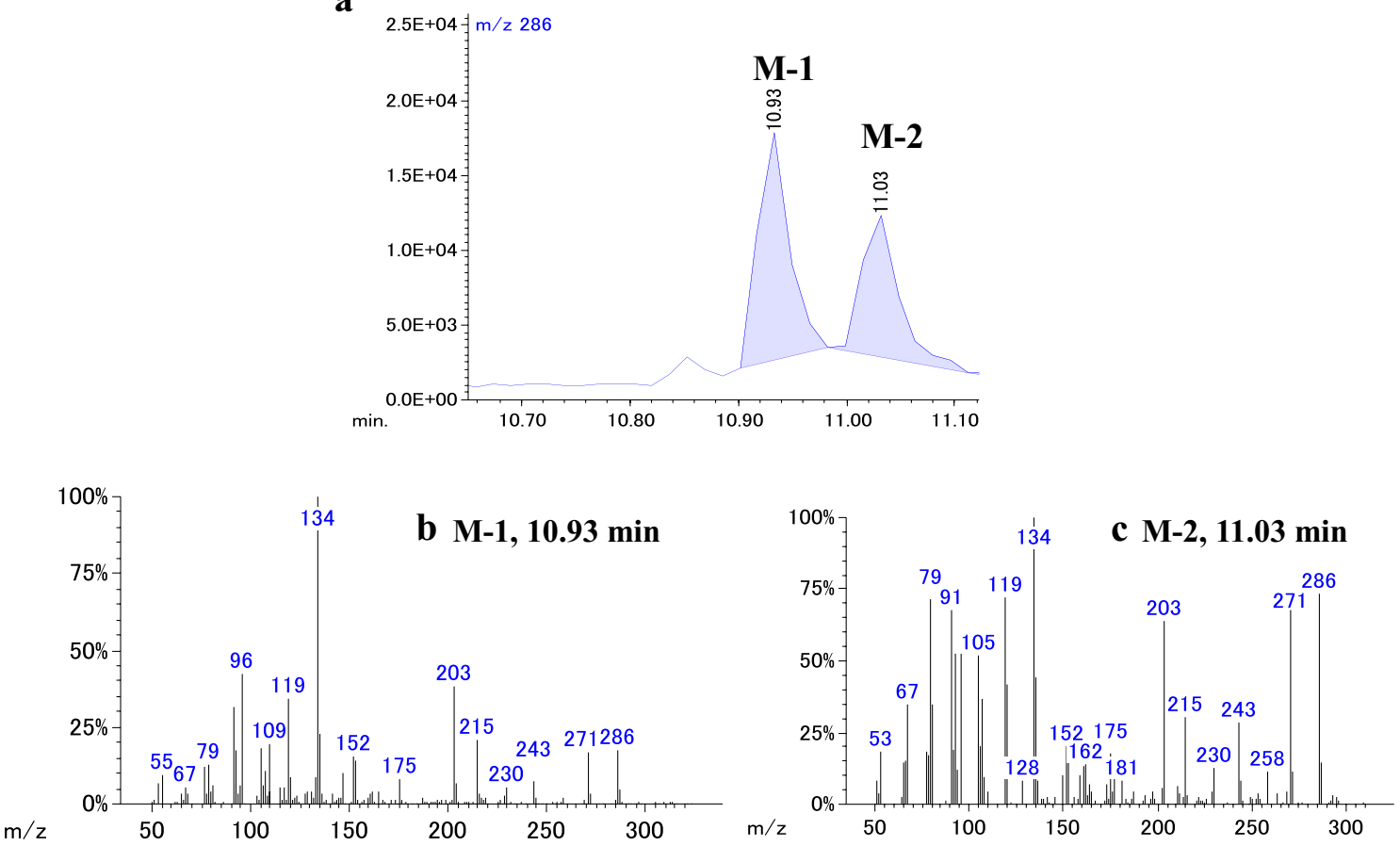

Fig. 4 XIC and mass spectra of decarbonylated metabolites of CBD formed by recombinant human cytochrome P450 3A4 (CYP3A4) 
Fig. 5 Decarbonylation of CBD by HLMs and CYP3A4, and derivatizations of $\mathrm{CBD}$ metabolites. EI-MS electron ionization mass spectrometry, TMS trimethylsilyl

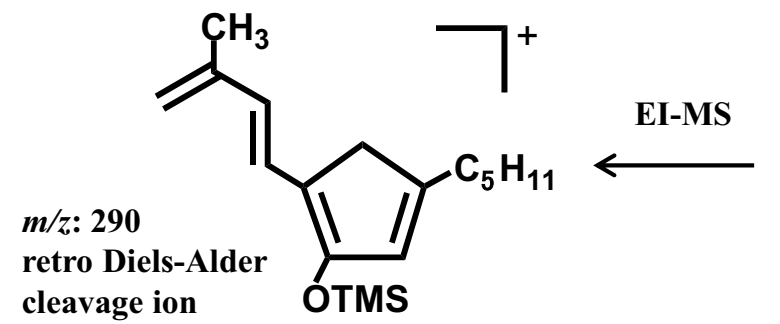

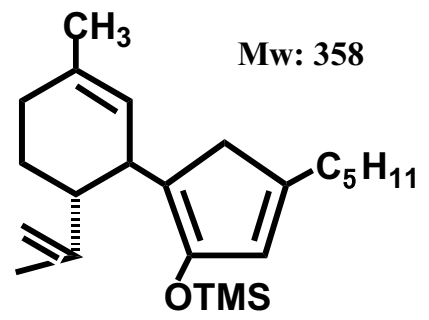

TMS
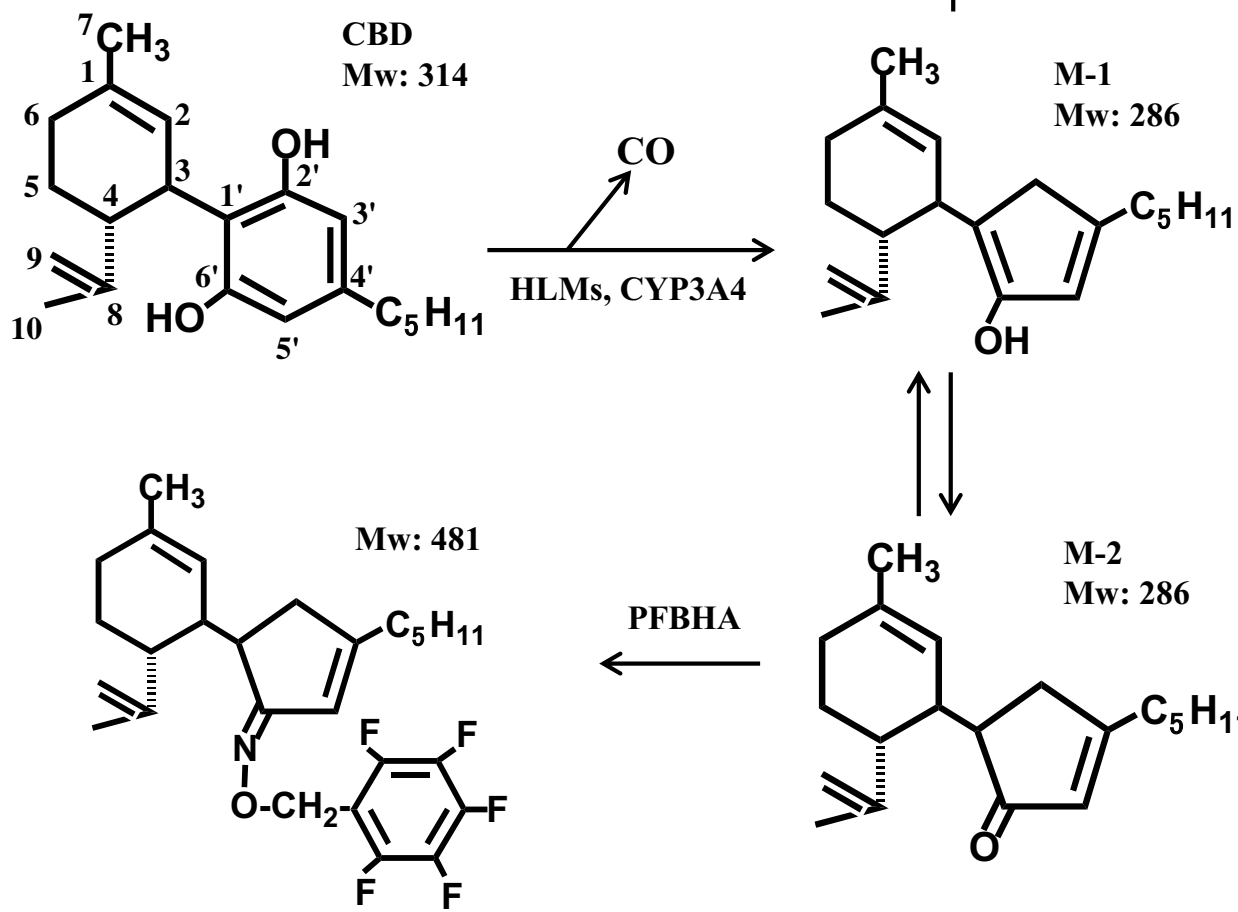

M-2

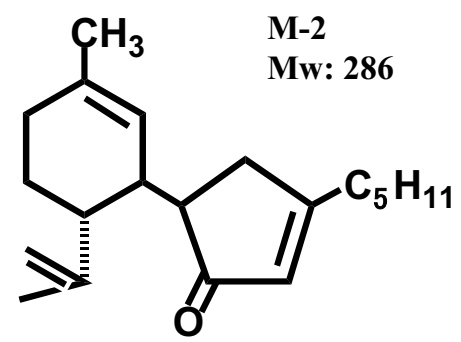

on the metabolic decarbonylation catalyzed by the human CYP enzyme, and further studies are needed to clarify the significance of this metabolic reaction of CBD in vivo, as well as the precise mechanism of the unique catalytic reaction by CYP3A4.

Acknowledgements This work was supported by a Grant-in-Aid for Scientific Research (C) from the Ministry of Education, Culture, Sports, Science, and Technology of Japan. The authors thank Mr. Yuji Hasegawa for GC-MS measurements.

\section{Compliance with ethical standards}

Conflict of interest There are no financial or other relations that could lead to a conflict of interest.

Ethical approval This article does not contain any studies with human participants or animals performed by any of the authors.
Open Access This article is distributed under the terms of the Creative Commons Attribution 4.0 International License (http://creativeco mmons.org/licenses/by/4.0/), which permits unrestricted use, distribution, and reproduction in any medium, provided you give appropriate credit to the original author(s) and the source, provide a link to the Creative Commons license, and indicate if changes were made.

\section{References}

1. Consroe P, Wolkin A (1977) Cannabidiol-anticonvulsant drug comparisons and interactions in experimentally induced seizures in rats. J Pharmacol Exp Ther 201:26-32

2. Hampson AJ, Grimaldi M, Axelrod J, Wink D (1998) Cannabidiol and (-) $\Delta^{9}$-tetrahydrocannabinol are neuroprotective antioxidants. Proc Nat Acad Sci USA 95:8268-8273

3. Mechoulam R, Parker LA, Gallily R (2002) Cannabidiol: an overview of some pharmacological aspects. J Clin Pharmacol $42: 11$ - $-19 S$ 
4. Compton DR, Rice KC, De Costa BR, Razdan RK, Melvin LS, Johnson MR, Martin BR (1993) Cannabinoid structure-activity relationships: correlation of receptor binding and in vivo activities. J Pharmacol Exp Ther 265:218-226

5. Collin C, Waberzinek G, Alsindi Z, Davies P, Powell K, Notcutt W, O'Leary C, Ratcliffe S, Nováková I, Zapletalova O, Piková J, Ambler Z (2010) A double-blind, randomized, placebo-controlled, parallel-group study of Sativex, in subjects with symptoms of spasticity due to multiple sclerosis. Neurol Res 32:451-459

6. Selvarajah D, Emery CJ, Gandhi R, Tesfaye S (2010) Randomized placebo-controlled double-blind clinical trial of cannabis-based medicinal product (Sativex) in painful diabetic neuropathy. Diabetes Care 33:128-130

7. Wade DT, Collin C, Scott C, Duncombe P (2010) Meta-analysis of the efficacy and safety of Sativex (nabiximols) on spasticity in people with multiple sclerosis. Mult Scler 16:707-714

8. Massi P, Solinas M, Cinquina V, Parolaro D (2013) Cannabidiol as potential anticancer drug. Br J Clin Pharmacol 75:303-312

9. Fisher T, Golan H, Schiby G, PriChen S, Smoum R, Moshe I, Peshes-Yaloz N, Castiel A, Waldman D, Gallily R, Mechoulam R, Toren A (2016) In vitro and in vivo efficacy of non-psychoactive cannabidiol in neuroblastoma. Curr Oncol 23:S15-S22

10. Devinsky O, Cilio MR, Cross H, Fernandez-Ruiz J, French J, Hill C, Katz R, Di Marzo V, Jutras-Aswad D, Notcutt WG, MartinezOrgado J, Robson PJ, Rohrback BG, Thiele E, Whalley B, Friedman D (2014) Cannabidiol: pharmacology and potential therapeutic role in epilepsy and other neuropsychiatric disorders. Epilepsia 55:791-802

11. Anderson CL, Evans VF, DeMarse TB, Febo M, Johnson CR, Carney PR (2017) Cannabidiol for the treatment of drug-resistant epilepsy in children: current state of research. J Pediatr Neurol 15:143-150

12. Nilsson I, Agurell S, Nilsson JLG, Widman M, Leander K (1973) Two cannabidiol metabolites formed by rat liver. J Pharm Pharmacol 25:486-487

13. Martin B, Nordqvist M, Agurell S, Lindgren J-E, Leander K, Binder M (1976) Identification of monohydroxylated metabolites of cannabidiol formed by rat liver. J Pharm Pharmacol 28:275-279

14. Harvey DJ, Brown NK (1990) In vitro metabolism of cannabidiol in seven common laboratory mammals. Res Commun Subst Abuse 11:27-37

15. Harvey DJ, Mechoulam R (1990) Metabolites of cannabidiol identified in human urine. Xenobiotica 20:303-320

16. Jiang R, Yamaori S, Takeda S, Yamamoto I, Watanabe K (2011) Identification of cytochrome P450 enzymes responsible for metabolism of cannabidiol by human liver microsomes. Life Sci $89: 165-170$

17. Watanabe K, Narimatsu S, Gohda H, Yamamoto I, Yoshimura H (1988) Formation of similar species to carbon monoxide during hepatic microsomal metabolism of cannabidiol on the basis of spectral interaction with cytochrome P-450. Biochem Pharmacol 37:4719-4726

18. Usami N, Watanabe K, Yamamoto I, Yoshimura H (1995) Formation of carbon monoxide during mouse hepatic microsomal oxidative metabolism of cannabidiol; identification and determination. Biol Pharm Bull 18:529-535

19. Aramaki H, Tomiyasu N, Yoshimura H, Tsukamoto H (1968) Forensic chemical study on marihuana. I. A detection method of the principal constituents by thin-layer and gas chromatographies. Chem Pharm Bull 16:822-826

20. Watanabe K, Miyamoto M, Yamaori S, Hasegawa K, Watanabe K, Suzuki O (2013) Human brain microsomes: their abilities to metabolize tetrahydrocannabinols and cannabinol. Forensic Toxicol 31:307-311

21. Kobayashi K, Tanaka M, Kawai S (1980) Gas chromatographic determination of low molecular-weight carbonyl compounds in aqueous solution as their $O$-(2,3,4,5,6-pentafluorobenzyl)-oximes. J Chromatogr 187:413-417

22. Budzikiewicz H, Alpin RT, Lightner DA, Djerassi C, Mechoulam R, Gaoni Y (1965) Massenspektroskopie und ihre Anwendung auf Strukturelle und Stereochemische Probleme-LXVIII: Massenspektroskopische Untersuchung der Inhaltstoffe von Haschisch. Tetrahedron 21:1881-1888

23. Harvey DJ (1987) Mass spectrometry of the cannabinoids and their metabolites. Mass Spectrom Rev 6:135-229

24. Yang H, Furutani Y, Kudo S, Hayashi J, Norinaga K (2016) Experimental investigation of thermal decomposition of dihydroxybenzene isomers: catechol, hydroquinone, and resorcinol. J Anal Appl Pyrolysis 120:321-329

25. Hemberger P, Custodis VBF, Bodi A, Gerber T, van Bokhoven JA (2017) Understanding the mechanism of catalytic fast pyrolysis by unveiling reactive intermediates in heterogenous catalysis. Nat Commun 8:15946

26. Cancilla DA, Hee SSQ (1992) $O$-(2,3,4,5,6-Pentafluorophenyl) methylhydroxylamine hydrochloride: a versatile reagent for the determination of carbonyl-containing compounds. J Chromatogr 627:1-16

Publisher's Note Springer Nature remains neutral with regard to jurisdictional claims in published maps and institutional affiliations. 